\title{
The Treponema pallidum haemagglutination (TPHA) test in biological false positive and leprosy sera
}

\author{
M. F. GARNER, J. L. BACKhOUSE, G. DASKALOPOULOS, AND J. L. WALSH \\ From the Institute of Clinical Pathology and Medical Research, Lidcombe, New South Wales, Australia
}

SYNOPSIS The Treponema pallidum haemagglutination (TPHA) test was carried out on 274 sera known to show biological false positive reactions to reagin tests for syphilis. The Treponema స్ pallidum immunization (TPI) and fluorescent treponemal antibody absorption (FTA-ABS) tests $\rightarrow$ were non-reactive on all these sera. Thirty-one or $11.3 \%$ showed reactive results in the TPHA test. N

Sera from 267 people who had lepromatous leprosy were also tested in the TPHA test. Fourteen ${ }_{\circ}^{\infty}$ sera were reactive in the TPHA, TPI, and FTA-ABS tests and were from people who had both syphilis and leprosy. Biological false positive reactions were shown by 26 of the leprosy sera, of which $\vec{D}$ three or $11.5 \%$ were also reactive in the TPHA test. A further four sera in the leprosy group were을. reactive only in the TPHA test.

The possible cause of false reactive TPHA test results is discussed.

It was concluded that where reagin and TPHA tests are reactive in a person who has no: history or clinical signs of syphilis, the serum should be referred for TPI and FTA-ABS testing.

At the present time three serological tests which can be regarded as specific for syphilis are available. These all use Treponema pallidum as antigen and are the Treponema pallidum immobilization (TPI) test, the fluorescent treponemal antibody absorption (FTA-ABS) test, and the latest addition to the group, the Treponema pallidum haemagglutination (TPHA) test. When a new test for treponemal infection is developed, apart from determining its specificity and sensitivity on syphilitic and yaws sera, its performance must be evaluated on that group of sera which have been shown to give biological false positive reactions. A serum which shows a biological false positive reaction is one in which the reagin detection tests are reactive and the treponemal tests non-reactive, and which comes from a patient with no history or clinical signs of treponemal infection.

As the TPHA test was to be evaluated, a biological false positive serum was considered to be one in which the cardiolipin Wassermann reaction (CWR) and/or Venereal Disease Research Laboratory (VDRL) tests were reactive and the TPI and FTA-ABS tests non-reactive. An increase in reagin in the serum to a level at which it can be detected by the CWR and VDRL test occurs in treponemal infections as well as Received for publication 31 January 1973. in a wide variety of unrelated conditions including $\stackrel{\mathbb{\Omega}}{\rightarrow}$ pregnancy, collagen diseases, rheumatoid arthritis, $\frac{0}{3}$ leprosy, following vaccination, etc. Reactive CWR and VDRL tests in sera from patients with tre-ponemal infection are not regarded as biological false positive reactions as these sera will also be요 reactive in the TPI and FTA-ABS tests.

This survey was carried out to compare the results 3 . of the TPHA test with those of the TPI and FTAABS tests on a group of known biological false $₹$ positive sera and on sera from leprosy patients.

\section{Materials and Methods}

The TPHA test was carried out on 274 sera showing biological false positive reactions, 267 sera from $N$ patients with lepromatous leprosy, and 329 presumed N normal sera. All sera were initially tested quali- tatively; on 24 sera a quantitative test was performed The presumed normal sera were all non-reactive in the CWR, VDRL, TPI, and FTA-ABS tests.

The reagents used in the TPHA test were manu- 0 factured by the Fuji Zoki Pharmaceutical Company,, 0 Tokyo, Japan. A manual micro technique which is simple to perform and read was used. This wast similar to that described by the Venereal Disease Research Laboratory, Atlanta, in 'Automated 
qualitative and quantitative micro-haemagglutination assay for Treponema pallidum antibodies (AMHA-Tp), provisional technique, modified October 20, 1970'.

Where discrepancies occurred between the TPI, FTA-ABS, and TPHA test results these were repeated to exclude technical error.

\section{Results}

\section{BIOLOGICAL FALSE POSITIVE SERA}

In the group of 274 biological false positive sera tested, the CWR was reactive in 87, the VDRL test in 251, and the TPHA test in 31 .

The 31 reactive TPHA tests occurred as follows: CWR and TPHA test reactive in two sera; VDRL and TPHA test reactive in 22 sera; and CWR, VDRL, and TPHA tests reactive in seven sera.

The biological false positive sera were divided into six groups: blood donors (63); antenatal patients (82); people recently vaccinated (11); patients with collagen disease (9); people from whom no history was obtainable (40); and patients with a wide variety of miscellaneous conditions (69). With the exception of the recently vaccinated, the TPHA test was reactive in some sera from all groups. Table I shows the results of the CWR, VDRL, and TPHA tests on the various groups of biological false positive sera examined.

Quantitative tests were carried out on 24 of the 31 biological false positive sera reactive in the TPHA test. Results were as follows: TPHA test titre 80, eight sera; titre 160 , five sera; titre 320 , four sera; titre 640 , three sera; titre 1280 , three sera; and titre 2560 , one serum.

\section{LEPROSY SERA}

The TPHA test was carried out on sera from 267 people who had lepromatous leprosy. Yaws was unknown among the people from whom the sera were collected. Fourteen sera were reactive in the TPHA, TPI, and FTA-ABS tests indicating that these came from patients who had both syphilis and leprosy.

The remaining 253 sera were non-reactive in the TPI and FTA-ABS tests, indicating that they were from people who did not have syphilis. Biological false positive reactions were shown by 26 of these sera: two in the CWR and 24 in the VDRL test. The TPHA test was reactive in three of these biological false positive sera as follows: TPHA and CWR (1), and TPHA and VDRL (2). A further four sera were reactive only in the TPHA test, these sera being non-reactive in the CWR, VDRL, TPI, and FTA-ABS tests (table II).

PRESUMED NORMAL SERA

Of the 329 sera in this group, one serum, from an antenatal patient, was reactive in the TPHA test.

\section{Diseussion}

Out of a total of 274 biological false positive sera, 31 were reactive in the TPHA test. These were in all

\begin{tabular}{|c|c|c|c|c|c|c|c|}
\hline \multirow[t]{2}{*}{ Sera } & \multirow[t]{2}{*}{ Total Sera } & \multicolumn{6}{|c|}{ Reactive Test Results } \\
\hline & & CWR Only & VDRL Only & $\begin{array}{l}C W R \text { and } \\
V D R L\end{array}$ & $\begin{array}{l}\text { CWR and } \\
T P H A\end{array}$ & $\begin{array}{l}\text { VDRL and } \\
T P H A\end{array}$ & $\begin{array}{l}C W R, V D R L \\
\text { and } T P H A\end{array}$ \\
\hline $\begin{array}{l}\text { Blood donors } \\
\text { Antenatal } \\
\text { Recent vaccination } \\
\text { Collagen disease } \\
\text { No history } \\
\text { Miscellaneous }\end{array}$ & $\begin{array}{r}63 \\
82 \\
11 \\
9 \\
40 \\
69\end{array}$ & $\begin{array}{r}2 \\
8 \\
- \\
4\end{array}$ & $\begin{array}{r}48 \\
50 \\
6 \\
5 \\
22 \\
34\end{array}$ & $\begin{array}{r}10 \\
14 \\
5 \\
3 \\
7 \\
18\end{array}$ & $\frac{-}{-}$ & $\begin{array}{r}3 \\
5 \\
5 \\
9\end{array}$ & $\begin{array}{l}\overline{5} \\
\overline{1} \\
1 \\
-\end{array}$ \\
\hline $\begin{array}{l}\text { Total biological false } \\
\text { positive sera }\end{array}$ & 274 & 21 & 165 & 57 & 2 & 22 & 7 \\
\hline
\end{tabular}

Table I Results of CWR, VDRL, and TPHA tests on 274 biological false positive sera

\begin{tabular}{|c|c|c|c|c|c|c|c|}
\hline & \multirow{2}{*}{$\begin{array}{l}\text { Total No. } \\
\text { Sera }\end{array}$} & \multicolumn{6}{|c|}{ Reactive Test Results } \\
\hline & & CWR Only & VDRL Only & TPHA Only & $\begin{array}{l}T P H A \text { and } \\
C W R\end{array}$ & $\begin{array}{l}\text { TPHA and } \\
\text { VDRL }\end{array}$ & $\begin{array}{l}T P H A, C W R \\
\text { and } V D R L\end{array}$ \\
\hline $\begin{array}{l}\text { TPI and FTA-ABS reactive } \\
\text { TPI and FTA-ABS non- } \\
\text { reactive }\end{array}$ & $\begin{array}{r}14 \\
253\end{array}$ & $\overline{1}$ & $\overline{22}$ & $\begin{array}{l}2 \\
4\end{array}$ & - & $\begin{array}{l}7 \\
2\end{array}$ & 5 \\
\hline
\end{tabular}

Table II Results of CWR, VDRL, and TPHA tests on 267 leprosy sera 
probability false positive TPHA test results. The biological false positive sera were from people with no history or clinical evidence of syphilis and each serum gave a non-reactive TPI and FTA-ABS test result. The FTA-ABS test is the first to become reactive in early syphilis even before the reagin tests, and both TPI and FTA-ABS tests are reactive in secondary, latent, and late syphilis. It is therefore unlikely that these 31 sera were from patients with syphilis.

Both the pathogenic and non-pathogenic treponemes share common or group antibodies. In the TPHA test this group antibody is removed from the test serum by Reiter treponeme components which are present in the absorbing diluent used in the test. Reiter treponeme components are used similarly in the FTA-ABS test to remove group antibody. However, this has not always been completely successful (Király, Jobbágy, and Kováts, 1967) and some false reactive FTA-ABS test results will occur. Thus it seems highly probable that some false reactive TPHA test results could occur due to failure of the Reiter treponemes to remove all group antibody from the test serum.

The significance of TPHA test titres has not been generally determined. The authors in an earlier study (Garner, Backhouse, Daskalopoulos, and Walsh, 1973) found no correlation between CWR and TPHA test titres and could not determine what was a high TPHA test titre. The qualitative TPHA test is carried out at a dilution of 1 in 80 . If low titres are considered to be $80,160,320$, and 640,20 of the 24 biological false positive sera titres were in this group.

There was no definite relationship between false reactive TPHA tests and the biological false positive group to which the patient belonged.

The TPHA test was reactive in all 14 sera from leprosy patients who were considered to have both leprosy and syphilis on the basis of reactive TPI and FTA-ABS tests. Of the 26 leprosy sera which showed BFP reactions three were reactive in the TPHA test. A further four sera were reactive only in the TPHA test. It is most probable that these seven reactive TPHA test results were false ones.

In the presumed normal group of 329 sera there was one reactive TPHA test result. This was from an antenatal patient who had no history or clinical signs of syphilis and in whom the reagin, TPI, and FTA-ABS tests were non-reactive. This again was presumably a false reactive TPHA test result.

In this survey the TPHA test was found to be reactive in $11.3 \%$ ( 31 of 274 ) of the biological false positive sera and in $11.5 \%$ (three of 26) of the leprosy sera which showed biological false positive reactions. This is not a satisfactory result if the TPHA test alone is to be used as the specific test to distinguish biological false positive from syphilitic sera. The results indicate that sera, which come from people with no history or clinical signs of syphilis, and are reactive in the reagin and TPHA tests, should have TPI and FTA-ABS tests carried out on them. If this is not done there is the possibility that a person could be mistakenly considered to have syphilis, when, in fact, the serum is showing a biological false positive reaction.

References

Garner, M. F., Backhouse, J. L., Daskalopoulos, G., and Walsh, J. L. (1973). The treponema pallidum haemagglutination test for syphilis: a comparison with the TPI and FTA-ABS tests. Brit. J. vener. Dis., 48, 470-473.

Kiıály, K., Jobbágy, A., and Kováts, L. (1967). Group antibodies in fluorescent treponemal antibody (FTA) test. J. invest. Derm. 48, 98-100.

Venereal Disease Research Laboratory, Atlanta (1970). Automated qualitative and quantitative micro-haemagglutination assay for Treponema pallidum antibodies (AMHA-Tp). Provisional technique, modified October 20,1970. 